\title{
Article \\ Implementation of Two-Stream Emission Model for L-Band Retrievals on the Tibetan Plateau
}

\author{
Xiaojing Wu
}

check for updates

Citation: $\mathrm{Wu}, \mathrm{X}$. Implementation of Two-Stream Emission Model for L-Band Retrievals on the Tibetan Plateau. Remote Sens. 2022, 14, 494. https://doi.org/10.3390/rs14030494

Academic Editor: Weimin Huang

Received: 13 December 2021

Accepted: 18 January 2022

Published: 20 January 2022

Publisher's Note: MDPI stays neutral with regard to jurisdictional claims in published maps and institutional affiliations.

Copyright: (C) 2022 by the author. Licensee MDPI, Basel, Switzerland. This article is an open access article distributed under the terms and conditions of the Creative Commons Attribution (CC BY) license (https:// creativecommons.org/licenses/by/ $4.0 /)$.
Key Laboratory of Ecosystem Network Observation and Modeling, Synthesis Research Center of Chinese Ecosystem Research Network, Institute of Geographic Sciences and Natural Resources Research, Chinese Academy of Sciences, Beijing 100101, China; wuxj@igsnrr.ac.cn

\begin{abstract}
This study assesses the suitability of the two-stream microwave emission model in simulating brightness temperature $\left(T_{\mathrm{B}}^{p}\right)$ and retrieving liquid water content $\left(\theta_{\text {liq }}\right)$ at L-band in combination with the four-phase dielectric model for both thawed and frozen soil. Both single (SCA) and double (DCA) channel algorithms are adopted using both ground-based ELBARA-III and spaceborne SMAP measurements conducted in a Tibetan grassland site. The ELBARA-III measured $T_{\mathrm{B}}{ }^{p}$ are smaller than the SMAP measurements in the warm season due to a lower value of average $\theta_{\text {liq }}$ presented within the ELBARA-III footprint. The two-stream emission model configured with SMAP vegetation and surface roughness parameterization underestimates both ELBARA-III and SMAP measured $T_{\mathrm{B}}{ }^{p}$ at horizontal polarization in the cold season, and overestimates the vertical polarized measurements $\left(T_{\mathrm{B}}{ }^{\mathrm{V}}\right)$ in the warm season. Implementation of a new surface roughness and vegetation parameterization resolves above deficiency, and the simulations capture better large-scale SMAP measurements in comparison to these performed for the ELBARA-III footprint. The dynamics of in situ $\theta_{\text {liq }}$ are better reproduced by retrievals using the SCA based on $T_{\mathrm{B}}{ }^{\mathrm{V}}$ measurements (SCA-V), whereby the SCA-V retrievals using the SMAP ascending overpass measurements shows the best results with an unbiased root-mean-square error (ubRMSE) of $0.035 \mathrm{~m}^{3} \mathrm{~m}^{-3}$ that outperforms the SMAP mission specification.
\end{abstract}

Keywords: Soil Moisture Active Passive (SMAP); L-band microwave radiometry; thawed and frozen soil conditions; liquid water content; grassland; Tibetan Plateau

\section{Introduction}

Passive microwave remote sensing at L-band $(1-2 \mathrm{GHz})$ is recognized as one of the most useful approaches for worldwide monitoring of surface soil moisture and freezethaw state [1,2]. Two currently operating satellite missions, i.e., the SMOS (Soil Moisture and Ocean Salinity) and SMAP (Soil Moisture Active Passive) launched, respectively, in 2009 by the European Space Agency (ESA) and in 2015 by the National Aeronautic and Space Administration (NASA), all use this technology to map global soil moisture. In the meantime, numerous studies have been devoted over the past decade to improve parameterizations of the commonly used $\tau-\omega$ microwave emission model [3] and retrieval of soil moisture by these two missions $[2,4,5]$.

The $\tau-\omega$ microwave emission model includes radiative components from both vegetation canopy and soil surface, whereby the vegetation canopy is generally treated as a single homogeneous "soft layer" [6,7]. This model is a zero-order solution of the microwave radiative transfer equations, which generally neglects multiple reflections between vegetation canopy and underground soil surface and does not follow the Kirchhoff's law [8]. In addition, the $\tau-\omega$ microwave emission model also neglects the multiple scattering processes in the vegetation canopy that is inadequate to represent canopy volume scattering [9-11]. To resolve this problem, a common way is to calibrate the vegetation parameters, i.e., the single-scattering albedo $\omega$ and vegetation optical depth $\tau$, to match brightness temperature $\left(T_{\mathrm{B}}{ }^{p}\right)$ measurements $[12,13]$ or simulations produced by numerical 
models [11,14-16]. As such, Kurum [17] showed that the canopy volume scattering can be accounted for by using the equivalent/effective vegetation parameters, and thus the firstorder solution of microwave radiative transfer equations can be appropriately reproduced by the zero-order $\tau-\omega$ model. However, calibration of the $\tau$ - $\omega$ model generally requires spaceborne, aircraft- or ground-based $T_{\mathrm{B}}{ }^{p}$ measurements, and the calibration also needs a network of in situ measurements across different climate and vegetation types with the assumption that the calibrated parameters can be applied to other similar geographical regions [9].

On the other hand, higher-order solution of the microwave radiative transfer equations has been developed to overcome the abovementioned deficiencies of zero-order $\tau-\omega$ emission model [6,9]. For instance, a two-stream emission model has recently been developed by Schwank et al. [6] according to the framework of MEMLS (Microwave Emission Model of Layered Snowpacks) model [18,19]. It's shown that the two-stream emission model that considers multiple scattering and reflection is physically more correct than the $\tau-\omega$ microwave emission model, whereby the "soft layer" assumption is removed [6]. Li et al. [7] and Schwank et al. [6] have recently compared the performances of two-stream and $\tau-\omega$ emission models in simulating the $T_{\mathrm{B}}{ }^{p}$ and retrieving soil moisture using groundbased and spaceborne measurements at local and global scales, respectively. The results have demonstrated the potential of replacing the $\tau-\omega$ model with the two-stream microwave emission model in the soil moisture retrieval algorithms due to its better performance. Specifically, the formulation of the single layer two-stream microwave emission model is as simple as the $\tau$ - $\omega$ emission model, whereby the former is also applicable to snow condition $[20,21]$ that makes it possible to implement a single microwave emission model for applications to different land conditions [7]. However, the performance of the two-stream microwave emission model for its application to frozen ground is still unknown, whereby the frozen ground is widely presented in the northern hemisphere, i.e., covers more than $50 \%$ of the land in the winter [22-24].

However, most of the currently widely used soil dielectric models, i.e., the semiempirical models proposed by Mironov et al. [25] and Dobson et al. [26], are only applicable to thawed soil condition. To date, there are three soil dielectric models that can be applicable to both thawed and frozen soil conditions, i.e., modified versions of above-mentioned Dobson [27] and Mironov [28] models and the four-phase dielectric model [29,30]. Mironov [28] demonstrated that their model provides a better estimate of soil permittivity in comparison to the model of Zhang et al. [27]. Recently, Zheng et al. [31] have shown that the four-phase dielectric mixing model is more suitable for simulating the $T_{\mathrm{B}}{ }^{p}$ on the Tibetan Plateau via comparing the performance of the above three soil dielectric models. The $T_{\mathrm{B}}{ }^{p}$ simulations are also sensitive to the vegetation and surface roughness parameterizations. The semi-empirical model proposed by Wang and Choudhury [32] has often been implemented to account for the impact of surface roughness, which adopts three parameters, namely, $Q$ represents the impact of polarization mixing, $h$ accounts for the increase/decrease in reflectivity affected by the surface roughness, and $N$ represents the angular dependence of reflectivity. On the other hand, the extinction and scattering effects of vegetation are usually expressed by the optical depth $\tau$ and effective scattering albedo $\omega^{p}$ [33]. In the baseline soil moisture retrieval algorithm of the SMAP mission, the $h$ and $\tau$ are, respectively, linearly correlated to the RMS height $(s)$ and vegetation water content (VWC), the $Q$ is assumed to be zero, and the $\omega$ is defined for specific vegetation types [34]. Recent studies [35-37] have suggested that the $Q$ is non-zero, and the empirical power-law relationship developed by Wigneron et al. [13] has also been widely implemented in the literature [35,36,38]. Recently, Zheng et al. [16,39] indicated that the SMAP algorithm overestimates the effect of vegetation canopy and underestimates the impact of surface roughness over the Tibetan Plateau, and a new parameterization has thus been proposed to address these problems. Similar findings have also been reported by Chaubell et al. [40].

In this study, we expand the application of the two-stream microwave emission model to both thawed and frozen soil conditions by incorporating the four-phase dielectric 
mixing model. Its performance in simulating L-band $T_{\mathrm{B}}{ }^{p}$ and retrieving liquid water content $\left(\theta_{\text {liq }}\right)$ has been tested using both spaceborne SMAP and ground-based ELBARA-III radiometry measured $T_{\mathrm{B}}{ }^{p}$ conducted in a Tibetan grassland site. The impact of different surface roughness and vegetation parameterizations on the $T_{\mathrm{B}}{ }^{p}$ simulation is also assessed, and the $\theta_{\text {liq }}$ is retrieved using both single (SCA) and double (DCA) channel algorithms. In Section 2, we show the simultaneous SMAP and ELBARA-III $T_{\mathrm{B}}{ }^{p}$ measurements, and Section 3 outlines the two-stream microwave emission model as well as the thereonbased $\theta_{\text {liq }}$ retrieval algorithms. The comparative analysis of SMAP and ELBARA-III $T_{\mathrm{B}}{ }^{p}$ measurements and their relationships with in situ $\theta_{\text {liq }}$ are presented in Section 4. Impacts of surface roughness and vegetation parameterizations on the $T_{\mathrm{B}}{ }^{p}$ simulations and $\theta_{\text {liq }}$ retrievals based on SMAP and ELBARA-III measured $T_{\mathrm{B}}{ }^{p}$ are investigated in Section 4 as well. The findings are summarized in the Section 5.

\section{Study Area and Observations}

\subsection{Maqu Station}

The Maqu soil moisture (SM) monitoring network is located within the Yellow River source region on the northeastern part of the Tibetan Plateau (Figure 1). The Maqu network is configured with about $30 \mathrm{SM}$ profile monitoring sites, which was chosen as one of the calibration/validation sites by the SMAP scientific team for evaluating the SMAP soil moisture retrievals [41]. The dominant land cover is alpine meadows, and the soil type is generally dominated by silt loam, whereby the average sand and clay percentage are about $30 \%$ and $10 \%$, and the average bulk density $\left(\rho_{\mathrm{b}}\right)$ is about $1 \mathrm{~g} \mathrm{~cm}^{-3}$ [16]. The elevations vary from 3400 to $3800 \mathrm{~m}$.

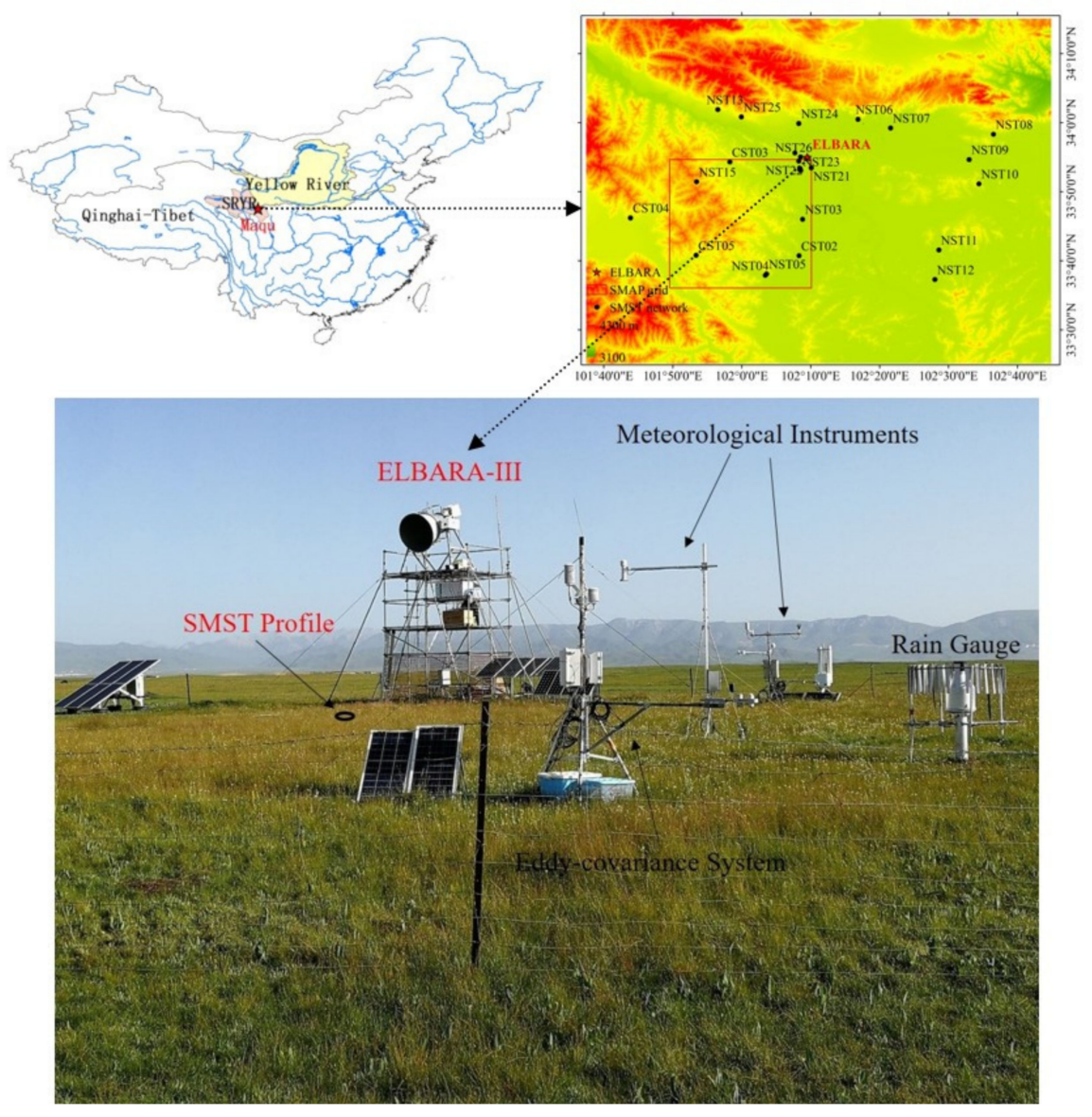

Figure 1. Locations of the Maqu in situ SM network and ELBARA-III monitoring site in the source region of Yellow River (SRYR). 
Each monitoring site records readings of SM at different soil depths ranging from 5 to $80 \mathrm{~cm}$ every $15 \mathrm{~min}$ using the Decagon 5TM probes. In the air, the 5TM sensors integrate a volume of $715 \mathrm{~mL}$ around the prong, with a maximum distance of $6 \mathrm{~cm}$ from the center of the sensor. In the soil, the zone of influence ranges from 3 to $4 \mathrm{~cm}$ from the middle prong of the 5TM sensors [42]. To further improve the measured accuracy of in situ soil liquid water contents $\theta_{\text {liq }}$ derived from the 5TM capacitance measurements, Dente et al. [43] have developed several calibration functions for specific soil types found across the Maqu area. Detailed description of the Maqu SM network is referred to Zheng et al. [44] and Zhang et al. [45].

\subsection{ELBARA-III Field Site}

For the purpose of evaluating the SMOS and SMAP measurements over the Tibetan Plateau, the L-band ELBARA-III radiometer [46] was setup within the Maqu in situ SM monitoring network (Figure 1) in January, 2016 [47,48]. The ELBARA-III radiometer has been deployed on a tower with $4.8 \mathrm{~m}$ height above the ground, and the beam waist of the antenna is about $6.5 \mathrm{~m}$ height. Both horizontal $\left(T_{\mathrm{B}}^{\mathrm{H}}\right)$ and vertical $\left(T_{\mathrm{B}} \mathrm{V}\right)$ polarized $T_{\mathrm{B}}{ }^{p}$ of ground have been measured for incidence angles ranging from $40^{\circ}$ to $70^{\circ}$ in steps of $5^{\circ}$ every $30 \mathrm{~min}$. Concurrent to the $T_{\mathrm{B}}{ }^{p}$ measurements, next to the radiometer tower SM and soil temperature (SMST) profiles have been measured by the 5TM probes as well, and micrometeorological measurements have also been performed in the field site. An additional description of the ELBARA-III observation site and the abovementioned in situ measurements was outlined by Zheng et al. [47,48].

\subsection{SMAP Products}

The SMAP satellite mission led by the NASA has been launched in January 2015, which is configured with an L-band $(1.41 \mathrm{GHz})$ radiometer and an L-band $(1.26 \mathrm{GHz})$ radar. The radar ceased operations in July 2015, while the radiometer continues to work and provides a spatial extent of about $40 \mathrm{~km}$ with off-nadir incidence angle $\psi \approx 40^{\circ}$ as expected.

Latest versions of Level $1 \mathrm{C}$ radiometer product and Level 2 radiometer SM product are utilized in this study, which is gridded on a $36 \mathrm{~km}$ Equal-Area Scalable Earth-2 (EASE2) grid and is available at https://nsidc.org/data/smap/smap-data.html (accessed on 12 December 2021). A centered validation grid pixel has been defined by the SMAP scientific team for the Maqu SM monitoring network to address the uncertainties related to the spatial mismatch between the SMAP soil moisture retrievals and the in situ references [41]. In Figure 1, it can be noted that the ELBARA-III monitoring station is placed at the upper right part of the SMAP validation grid. The $T_{\mathrm{B}}{ }^{p}$ measurements of SMAP during both ascending (6 PM) and descending (6 AM) overpasses are used in this study, and the data during the period from August 2016 to July 2017 are extracted for the validation grid pixel. There are about 360 SMAP measurements that are available for the presented research.

Both SMAP and ELBARA-III measured $T_{\mathrm{B}}{ }^{p}$ and the corresponding footprint average $\theta_{\text {liq }}$ used in this study is provided as Supplementary Material. Please find the Supplementary Table S1 for the details.

\section{Methods}

\subsection{Two-Stream Microwave Emission Model}

The two-stream emission model developed by Schwank et al. [6] is implemented to simulate the land surface emission in this study:

$$
\begin{gathered}
T_{\mathrm{B}}^{p}=T_{\mathrm{G}} \cdot e_{\mathrm{S}}^{p}+T_{\mathrm{v}} \cdot e_{\mathrm{v}}^{p}+T_{\mathrm{sky}} \cdot e_{\mathrm{sky}}^{p} \\
e_{\mathrm{s}}^{p}=\gamma_{\mathrm{v}}\left(1-r^{p}\right) /\left(1-r^{p} r_{\mathrm{v}}\right), \\
e_{\mathrm{v}}^{p}=\left(1-r_{\mathrm{v}}-\gamma_{\mathrm{v}}\right)\left(1-r^{p} r_{\mathrm{v}}+r^{p} \gamma_{\mathrm{v}}\right) /\left(1-r^{p} r_{\mathrm{v}}\right), \\
e_{\mathrm{sky}}^{p}=1-e_{\mathrm{s}}^{p}-e_{\mathrm{v}}^{p},
\end{gathered}
$$




$$
\begin{aligned}
& \gamma_{\mathrm{v}}=\frac{2 \cdot \exp \left(\tau \sqrt{1-\omega^{2}} / \cos \psi\right) \cdot\left[1-\omega^{2}+\sqrt{1-\omega^{2}}\right]}{\exp \left(2 \tau \sqrt{1-\omega^{2}} / \cos \psi\right) \cdot\left[2-\omega^{2}+2 \sqrt{1-\omega^{2}}\right]-\omega^{2}}, \\
& r_{\mathrm{v}}=\frac{\omega \cdot\left[\exp \left(2 \tau \sqrt{1-\omega^{2}} / \cos \psi\right)-1\right] \cdot\left[1+\sqrt{1-\omega^{2}}\right]}{\exp \left(2 \tau \sqrt{1-\omega^{2}} / \cos \psi\right) \cdot\left[2-\omega^{2}+2 \sqrt{1-\omega^{2}}\right]-\omega^{2}},
\end{aligned}
$$

where $p$ indicates the polarization of microwave emission $(p=\mathrm{H}$, horizontal; $p=\mathrm{V}$, vertical), $T_{\mathrm{V}}$ and $T_{\mathrm{G}}$ are the effective vegetation and soil temperature $(\mathrm{K}), T_{\text {sky }}$ represents the sky brightness temperature (K), $e_{\mathrm{s}}{ }^{p}, e_{\mathrm{v}}{ }^{p}$ and $e_{\text {sky }}{ }^{p}$ are emissivity (-) of soil, vegetation and sky, $r_{\mathrm{v}}$ represents the vegetation reflectivity $(-), \gamma_{\mathrm{v}}$ represents the transmissivity of vegetation canopy $(-), r^{p}$ represents the rough soil reflectivity $(-), \omega$ represents the effective scattering albedo $(-), \tau$ represents the vegetation optical depth $(-)$, and $\psi$ is the incidence (observation) angle $\left({ }^{\circ}\right)$. The $T_{\text {sky }}$ can be estimated by an empirical approach using air temperature and elevation as input [49], which is ignored in this study due to the fact that its value is very small at L-band $(\approx 5 \mathrm{~K})[6]$.

The estimation of $r^{p}$ is formulated as [50]:

$$
r^{p}=\left[(1-Q) \cdot r_{\mathrm{s}}^{p}+Q \cdot r_{\mathrm{s}}^{q}\right] \cdot \exp \left(-h \cdot \cos ^{N} \psi\right),
$$

where $q$ indicates the polarization of microwave emission $(q=\mathrm{H}$, horizontal; $q=\mathrm{V}$, vertical), $r_{\mathrm{s}}{ }^{p}$ and $r_{\mathrm{s}}{ }^{q}$ are the specular reflection coefficients $(-), N$ represents the angular effect on the reflectivity $(-), h$ takes into account the intensity effect $(-)$, and $Q$ refers to the impact of polarization mixing (-). The $r_{\mathrm{s}}{ }^{p}$ and $r_{\mathrm{s}}{ }^{q}$ are estimated by the Fresnel's equations [33] using the effective soil permittivity $\varepsilon_{\mathrm{s}}$ as input:

$$
\begin{gathered}
r_{\mathrm{s}}^{H}=\left|\frac{\cos \psi-\sqrt{\varepsilon_{s}-\sin ^{2} \psi}}{\cos \psi+\sqrt{\varepsilon_{s}-\sin ^{2} \psi}}\right|^{2}, \\
r_{\mathrm{s}}^{V}=\left|\frac{\varepsilon_{s} \cos \psi-\sqrt{\varepsilon_{s}-\sin ^{2} \psi}}{\varepsilon_{s} \cos \psi+\sqrt{\varepsilon_{s}-\sin ^{2} \psi}}\right|^{2},
\end{gathered}
$$

The soil permittivity $\varepsilon_{\mathrm{S}}\left(\varepsilon_{\mathrm{S}}=\varepsilon^{\prime}{ }_{\mathrm{S}}+\mathrm{i} \cdot \varepsilon^{\prime \prime}{ }_{\mathrm{S}}\right)$ of the thawed or frozen soil condition is simulated by the four-phase soil dielectric model as [30,31,51]:

$$
\varepsilon_{\mathrm{s}}^{\eta}=\left(\theta_{\mathrm{s}}-\theta\right) \varepsilon_{\text {air }}^{\eta}+\theta_{\text {liq }} \varepsilon_{\mathrm{w}}^{\eta}+\left(\theta-\theta_{\text {liq }}\right) \varepsilon_{\text {ice }}^{\eta}+\left(1-\theta_{\mathrm{s}}\right) \varepsilon_{\text {matrix }}^{\eta}
$$

where $\theta_{\mathrm{s}}$ represents the porosity $\left(\mathrm{m}^{3} \mathrm{~m}^{-3}\right), \theta$ represents the soil total water content $\left(\mathrm{m}^{3} \mathrm{~m}^{-3}\right)$ that derived from the in situ $\theta_{\text {liq }}\left(\mathrm{m}^{3} \mathrm{~m}^{-3}\right)$ as in Zheng et al. [52]. The exponent $\eta$ is specified as 0.5 , and the complex permittivity of ice, dry soil matrix and air are taken from Schwank et al. [30] as $\varepsilon_{\text {ice }}=3.2+\mathrm{i} \cdot 0.1, \varepsilon_{\text {matrix }}=5.5+\mathrm{i} \cdot 0.2$ and $\varepsilon_{\text {air }}=1$. The complex permittivity of liquid water $\left(\varepsilon_{\mathrm{w}}\right)$ is computed using the Dobson et al. [26] model as in Zheng et al. [47].

During the SMAP overpass (6 PM or $6 \mathrm{AM}$ ), it's reasonable to assume that the near-surface, vegetation and air are in thermal equilibrium with $T_{\mathrm{V}} \approx T_{\mathrm{G}}$, which can be represented by the effective soil temperature $T_{\text {eff. }}$. Here, we compute $T_{\text {eff }}$ according to Choudhury et al. [53] from available in situ SMST information as:

$$
\begin{gathered}
T_{\text {eff }}=\int_{0}^{\infty} T_{\mathrm{S}}(z) \alpha(z) \exp \left[-\int_{0}^{z} \alpha\left(z^{\prime}\right) d z^{\prime}\right] d z, \\
\alpha(z)=\frac{4 \pi}{\lambda} \cdot \operatorname{Im}\left(\sqrt{\varepsilon_{\mathrm{s}}}\right),
\end{gathered}
$$

where $\lambda$ is the vacuum wavelength $(\mathrm{cm}), T_{\mathrm{s}}(z)$ is the soil temperature $(\mathrm{K})$, and $\alpha(z)$ is the attenuation coefficient (-) at soil depth $z$. 
In this study, the surface roughness parameter $N$ in Equation (7) and vegetation parameter $\omega$ in Equations (5) and (6) are set equal to 2 and 0.05 as the SMAP retrieval algorithm [34] for grassland, and two parameterizations are adopted to estimate the parameters $\tau$ in Equations (5) and (6), as well as $h$ and $Q$ in Equation (7). One is to implement the parameterization adopted by the SMAP retrieval algorithm [34] (hereafter "SMAP parameterization") as:

$$
\begin{aligned}
& \tau=b \cdot \mathrm{VWC}, \\
& \mathrm{VWC}=1.9134 \cdot \mathrm{NDVI}^{2}-0.3215 \cdot \mathrm{NDVI} \\
& +1.5 \cdot(\mathrm{NDVI}-0.1) /(1-0.1) \\
& h=0.01 \cdot s \text {, } \\
& Q=0,
\end{aligned}
$$

where NDVI refers to the normalized difference vegetation index $(-)$, VWC refers to the vegetation water content $(-)$, and $s$ represents the standard deviation of surface roughness height $(\mathrm{mm})$. The parameters $b$ and $s$ are set equal to $0.13(-)$ and $15.6 \mathrm{~mm}$ as the SMAP retrieval algorithm [34] for grassland, which lead to the value of 0.156 for the $h$ according to Equation (15).

The other is to implement the new vegetation and surface roughness parameterization newly developed by Zheng et al. [16,39] (hereafter "Zheng's parameterization") which showed that the SMAP parameterization underestimates the impact of surface roughness and overestimates the effect of vegetation in the Tibetan grassland and desert ecosystems:

$$
\begin{gathered}
\tau=0.025 \cdot \mathrm{LAI}, \\
h=\left(\frac{0.9437 \cdot s}{0.8865 \cdot s+2.2913}\right)^{6}, \\
Q=0.1771 \cdot h,
\end{gathered}
$$

where LAI is the leaf are index $\left(\mathrm{m}^{2} \mathrm{~m}^{-2}\right), s$ is also set equal to $15.6 \mathrm{~mm}$ as the SMAP retrieval algorithm [34] for grassland, which leads to values of 0.58 and 0.1 for the $h$ and $Q$ according to Equations (18) and (19).

The needed NDVI and LAI in this study are obtained from the MODIS MOD13A2 [54] and MOD15A2 [55] products, respectively. Figure 2 presents the time series of vegetation optical depth $\tau$ estimated by the SMAP and Zheng's parameterizations for the SMAP descending overpass from August 2016 and July 2017 that is consistent with both SMAP and ELBARA-III measurements. The $\tau$ estimates, based on the SMAP parameterization, are considerably larger than those computed by the new parameterization of Zheng et al. [16]. On the contrary, Zheng's parameterization tends to produce larger values of $Q$ and $h$ in comparison to SMAP parameterization, i.e., 0.1 vs. 0 for the $Q$, and 0.58 vs. 0.156 for the $h$.

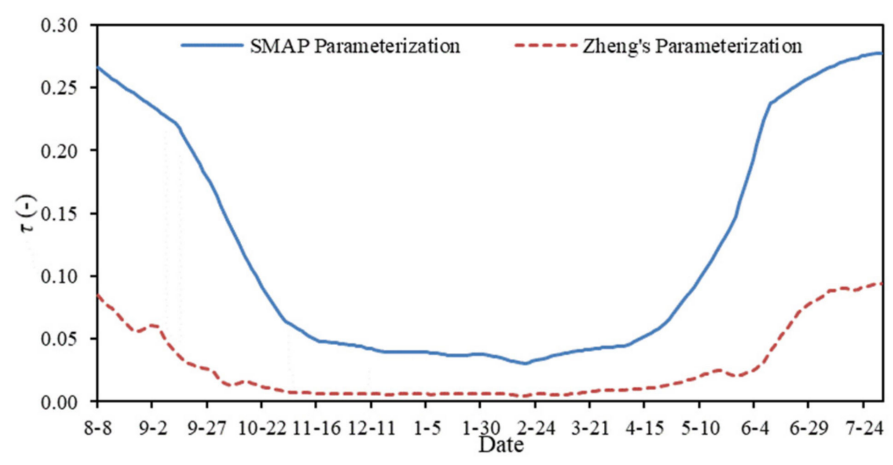

Figure 2. Time series of $\tau$ estimates derived from SMAP and Zheng's parameterizations between August 2016 and July 2017 for the SMAP descending overpass. 
To help the reader understand how the two-stream emission model is implemented with either SMAP or Zheng's vegetation and surface roughness parameterization to simulate the $T_{\mathrm{B}}{ }^{p}$, a sample computation is provided as Supplementary Material. Please find the Supplementary Table S2 for the details.

\subsection{Soil Liquid Water Content Retrieval Algorithms}

Both the single channel soil moisture retrieval algorithm (SCA) using either the $T_{B}{ }^{H}$ (SCA-H) or $T_{\mathrm{B}}{ }^{\mathrm{V}}$ (SCA-V) measurements and double channel algorithm (DCA) using both $T_{\mathrm{B}}{ }^{\mathrm{V}}$ and $T_{\mathrm{B}}{ }^{\mathrm{H}}$ measurements implemented by the SMAP retrieval algorithm [34] are adopted to retrieve the $\theta_{\text {liq }}$ in this study for both thawed and frozen soil conditions. The twostream emission model is adopted for the forward land emission modelling with the implementation of the four-phase soil dielectric model (see Section 3.1), whereby the better performance of vegetation and surface roughness parameterization (SMAP or Zheng's parameterization) is implemented to estimate the parameters $\tau, h$, and $Q$. Additional information about the SCA and DCA retrieval approaches is referred to-O'Neill et al. [34].

\section{Results}

\subsection{Comparisons between SMAP and ELBERA-III $T_{B}{ }^{p}$ Observations}

Figure 3 presents the time series of $T_{B}{ }^{H}$ and $T_{B}{ }^{V}$ measurements collected by the SMAP and ELBARA-III radiometer at the observation angle $\psi$ of $40^{\circ}$. The SMAP measurements performed between August 2016 and July 2017 during both ascending and descending overpasses are considered, and the ELBARA-III measurements closest to the overpasses of SMAP are extracted for the comparison. The data gap noted for the ELBARA-III measurements is caused by power supply failures. Figure 3 also presents the statistical errors estimated between the SMAP and ELBARA-III measurements, which includes the rootmean-square error (RMSE), bias, unbiased RMSE (ubRMSE) and Pearson product moment correlation coefficient (R). Figure 4 further shows the spatial $\theta_{\text {liq }}$ averages at $5 \mathrm{~cm}$ soil depth taken from the in situ data collected within the footprints of ELBARA-III and SMAP measurements (Figure 1). The error statistics estimated between the in situ $\theta_{\text {liq }}$ representative of the ELBARA-III and the SMAP footprints are shown in Figure 4 as well.
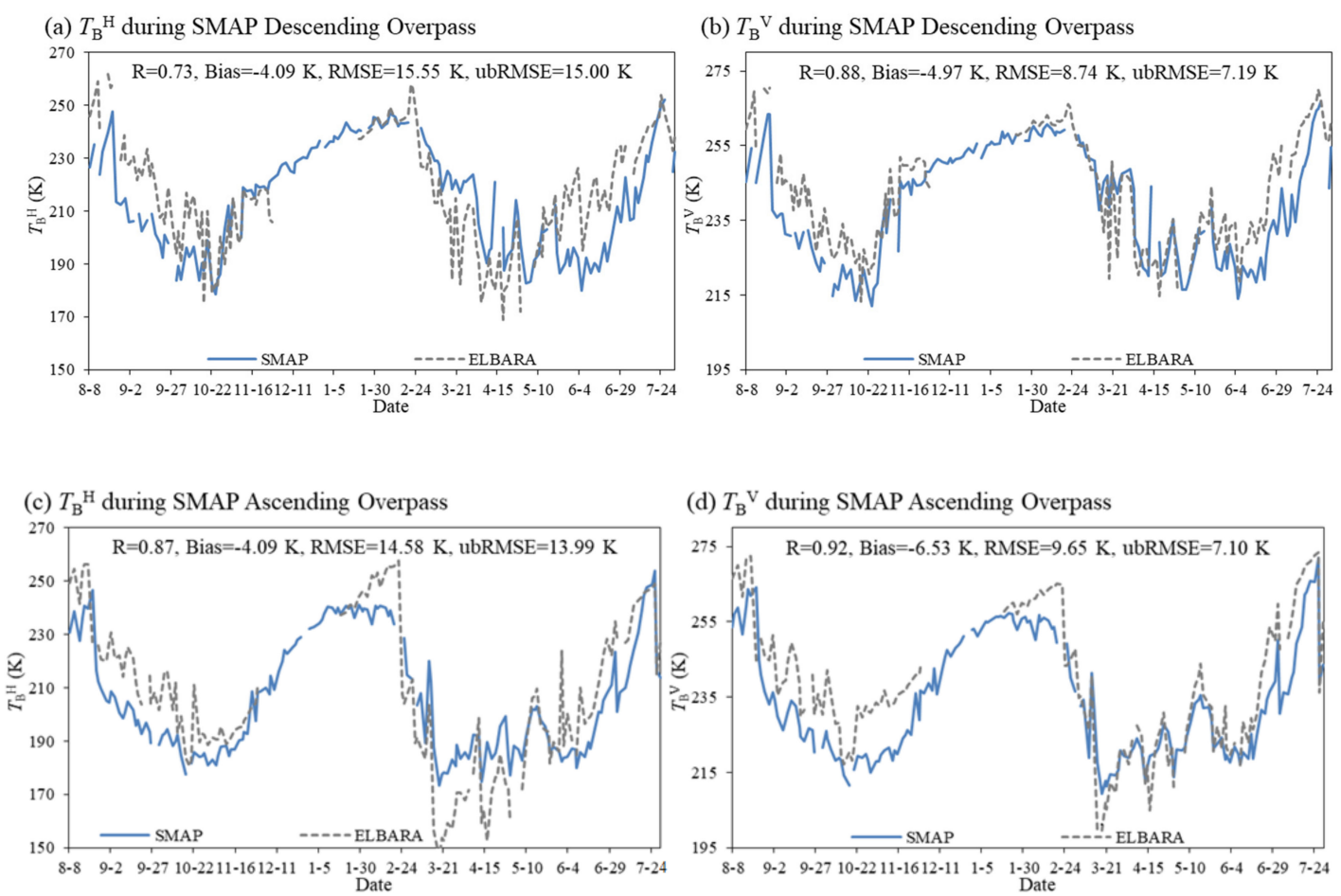

Figure 3. Time series of SMAP and ELBARA-III measured $(\mathbf{a}, \mathbf{c}) T_{\mathrm{B}}{ }^{\mathrm{H}}$ and $(\mathbf{b}, \mathbf{d}) T_{\mathrm{B}}{ }^{\mathrm{V}}$ during the SMAP $(\mathbf{a}, \mathbf{b})$ descending and $(\mathbf{c}, \mathbf{d})$ ascending overpasses between August 2016 and July 2017. 

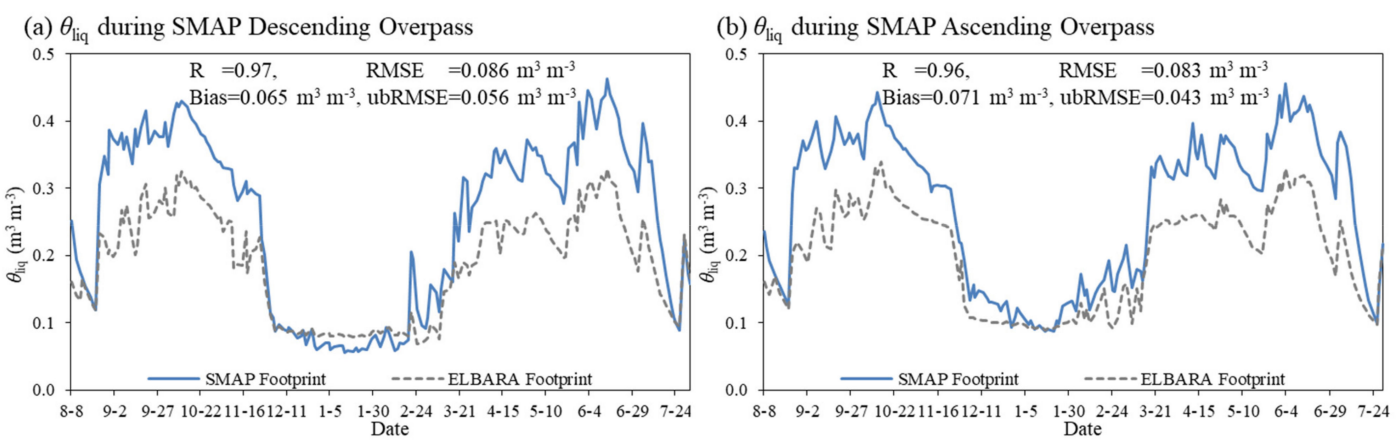

Figure 4. Time series of averaged $\theta_{\text {liq }}$ at a depth of $5 \mathrm{~cm}$ taken from in situ data collected within ELBRA-III and SMAP footprints during the (a) descending and (b) ascending overpasses of SMAP mission between August 2016 and July 2017.

The $\theta_{\text {liq }}$ dynamics of the ELBARA-III and SMAP footprints are comparable to each other (Figure 4). Pearson's correlation coefficient $R$ between the two in situ $\theta_{\text {liq }}$ averages is high ( $\mathrm{R} \geq 0.96)$ during the SMAP overpasses. In general, the soil is unfrozen and wet from May to October (i.e., warm season), while it appears as frozen and dry between November and April (i.e., cold season). In the warm season, the average $\theta_{\text {liq }}$ of the ELBARAIII footprint is generally smaller than that within the SMAP footprint, which is due to the fact that the soil porosity and water holding capacity are higher within the SMAP footprint caused by larger organic matter contents found in the soil [43,44]. Comparison of Figures 3 and 4 shows that both ELBARA-III and SMAP measured dynamics of $T_{\mathrm{B}}{ }^{p}$ generally follow the $\theta_{\text {liq }}$ variations in the warm season, whereby the $T_{\mathrm{B}}{ }^{p}$ increase with decreasing $\theta_{\text {liq }}$ (e.g., July 2017) and vice versa (e.g., September 2016). In the cold season, the $\theta_{\text {liq }}$ sharply decreases due to soil freezing between November and February that results in the increase in $T_{\mathrm{B}}{ }^{p}$, while thawing of soil ice between February and April leads to increase in $\theta_{\text {liq }}$ and thus a decrease in $T_{\mathrm{B}}{ }^{p}$. Generally, the SMAP and ELBARA-III measured $T_{\mathrm{B}}{ }^{p}$ show high correlation as indicated by $\mathrm{R} \geq 0.87$ except for the $T_{\mathrm{B}}{ }^{\mathrm{H}}$ during the SMAP descending overpass (Figure $3 a$ ). In addition, the ELBARA-III measured $T_{\mathrm{B}}{ }^{p}$ are generally larger than the SMAP measurements between June and October due to the fact that $\theta_{\text {liq }}$ of ELBARA-III footprint is smaller than that of SMAP footprint.

\subsection{Relations between $T_{B}{ }^{p}$ and $\theta_{\text {liq }}$ Observations}

Figure 5 shows the relations of the $T_{\mathrm{B}}{ }^{\mathrm{H}}$ (left panel), $T_{\mathrm{B}} \mathrm{V}$ (middle panel) and polarization ratio $\left(\mathrm{PR} \equiv\left(T_{\mathrm{B}} \mathrm{V}-T_{\mathrm{B}}{ }^{\mathrm{H}}\right) /\left(T_{\mathrm{B}} \mathrm{V}+T_{\mathrm{B}}{ }^{\mathrm{H}}\right)\right.$, right panel) extracted from the ELBARA-III and SMAP measurements at $\psi=40^{\circ}$ versus the corresponding footprint averaged $\theta_{\text {liq }}$. The analysis is conducted for the cold (November-April) and warm (May-October) seasons during the SMAP descending (top panel) and ascending overpasses (bottom panel) between 2016 and 2017, respectively. The corresponding $R$ are also shown in Figure 5. Compared to the ELBARA-III measurements, the $T_{\mathrm{B}} \mathrm{H}, T_{\mathrm{B}} \mathrm{V}$ and PR obtained from the SMAP measurements show higher correlations with footprint averaged $\theta_{\text {liq }}$ for both cold and warm periods during both SMAP descending and ascending overpasses as indicated by smaller scatters and thus higher $R$ values (Figure 5).

The correlations between both ELBARA-III and SMAP measured $T_{\mathrm{B}} \mathrm{V}$ and the footprint averaged $\theta_{\text {liq }}$ in the warm season are best explained by a linear function, with $R^{2}$ values larger than 0.81 during both SMAP descending and ascending overpasses. In contrast, the largest scatter is found for the plot with the ELBARA-III derived PR versus the footprint averaged $\theta_{\text {liq. }}$. In the cold season, the SMAP measurements (i.e., $T_{\mathrm{B}} \mathrm{H}, T_{\mathrm{B}} \mathrm{V}$ and PR) are better linked to the $\theta_{\text {liq }}$ measurements during the SMAP ascending overpass, while the ELBARAIII measurements show better agreement with the in situ $\theta_{\text {liq }}$ during the SMAP descending overpass. In general, higher $\mathrm{R}^{2}$ values are found between both SMAP and ELBARA-III measured $T_{\mathrm{B}} \mathrm{H}$ and the $\theta_{\text {liq }}$ measurements in the cold period, and the relationship between 
SMAP measured $T_{\mathrm{B}} \mathrm{V}$ and the in situ $\theta_{\text {liq }}$ shows the highest $\mathrm{R}^{2}$ value during the SMAP ascending overpass.
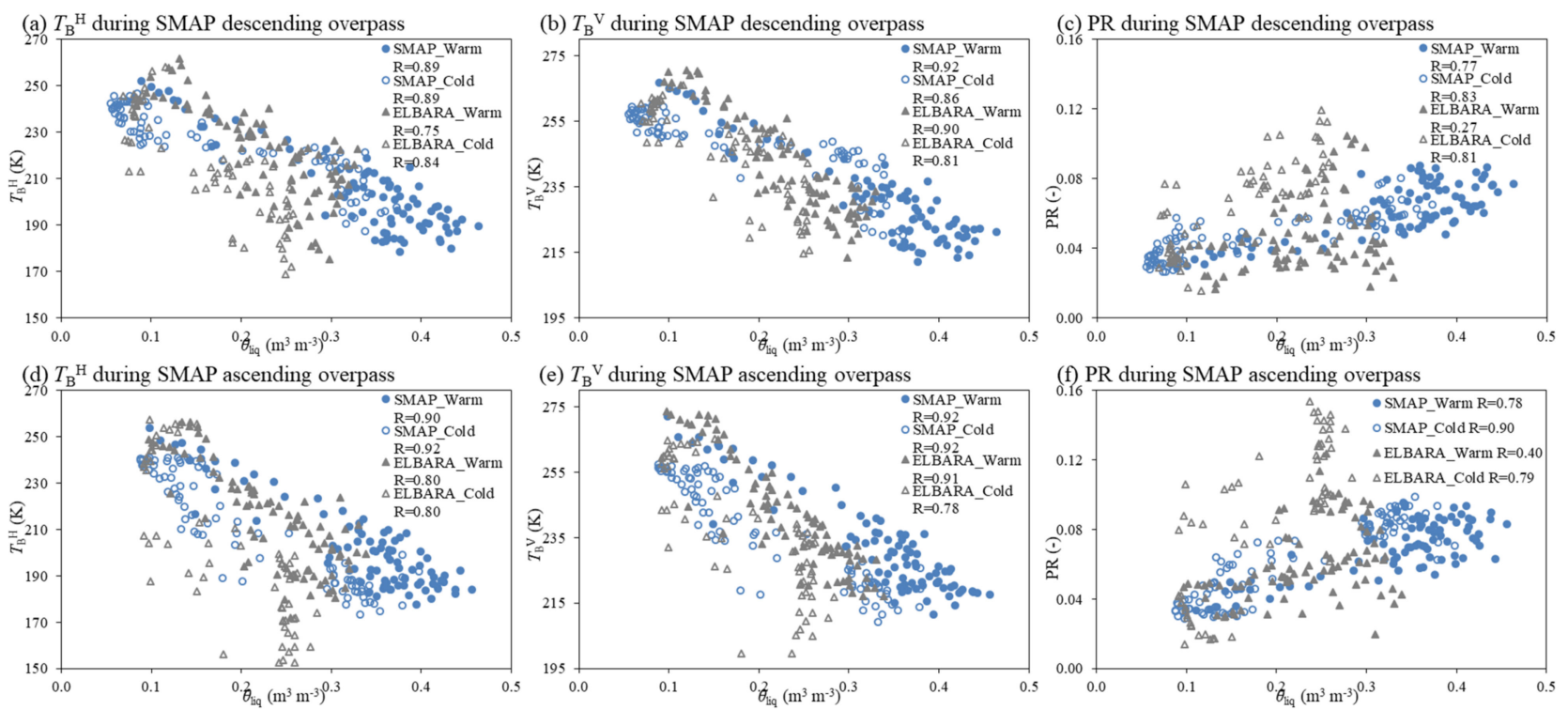

Figure 5. Scatter plots of the $T_{\mathrm{B}}{ }^{\mathrm{H}}(\mathbf{a}, \mathbf{d}), T_{\mathrm{B}} \mathrm{V}(\mathbf{b}, \mathbf{e})$ and polarization ratio (PR) (c,f) obtained from both SMAP and ELBRA-III measurements versus $\theta_{\text {liq }}$ at a depth of $5 \mathrm{~cm}$ taken from in situ data collected within the SMAP and ELBRA footprints for the SMAP descending $(\mathbf{a}-\mathbf{c})$ and ascending (d-f) overpasses in the cold (November-April) and warm (May-October) seasons. The corresponding correlations (R) are also shown.

\subsection{Brightness Temperature Simulation}

To investigate the performance of the two-stream emission model and its sensitivity to different vegetation and surface roughness parameterizations, two simulations are performed with the two-stream model using either the SMAP (Sim1) or Zheng's (Sim2) parameterization (see Section 3.1). The SMST input data are specified as the arithmetic average of in situ data collected within either the ELBARA-III or the SMAP footprint (Section 2) closest to the SMAP overpasses for matching the $T_{\mathrm{B}}{ }^{p}$ simulations with either the SMAP or the ELBARA-III measurements.

Figure 6 shows the time series of $\mathrm{SMAP}_{\mathrm{B}}{ }^{p}$ measurements and simulations produced from both Sim 1 and Sim 2 performed for the SMAP footprint between August 2016 and July 2017 for the SMAP descending and ascending overpasses. The corresponding statistical errors estimated between the measured and simulated $T_{\mathrm{B}}{ }^{p}$ are provided in Table 1 . The SMAP $T_{\mathrm{B}}{ }^{\mathrm{H}}$ measurements are underestimated by the two-stream microwave emission model configured with the vegetation and surface roughness parameterizations of SMAP mission (Sim1) for the cold season (November-April), and the SMAP measured $T_{\mathrm{B}} \mathrm{V}$ are overestimated for the warm season (June-October). These discrepancies are strongly reduced when using Zheng's surface roughness and vegetation parameterizations within the two-stream model (Sim2). Particularly, the ubRMSE are reduced by, on average, about $44 \%$ and $29 \%$ for the $T_{\mathrm{B}} \mathrm{H}$ and $T_{\mathrm{B}} \mathrm{V}$. This demonstrates that the impact of surface roughness is underestimated by the Sim 1 based on the SMAP parameterizations with the implementation of lower values of $Q$ and $h$, and the vegetation effect is overestimated due to the usage of higher $\tau$ values (Figure 2) in accordance with the findings of Zheng et al. [16]. In addition, it can be noted that both $\operatorname{Sim} 1$ and $\operatorname{Sim} 2$ underestimate the SMAP measured $T_{\mathrm{B}}{ }^{\mathrm{H}}$ and $T_{\mathrm{B}}{ }^{\mathrm{V}}$ for the transition seasons with soil thawing from March and April and soil freezing between October and November and during the SMAP descending overpass. However, such underestimations disappeared in the SMAP ascending overpass. The SMAP $T_{\mathrm{B}} \mathrm{V}$ measurements are better captured by both $\operatorname{Sim} 1$ and $\operatorname{Sim} 2$ in terms of error statistics in 
comparison to the $T_{\mathrm{B}}{ }^{\mathrm{H}}$ simulation due to the higher correlation with the measured $\theta_{\text {liq }}$ as shown in Section 4.2 .

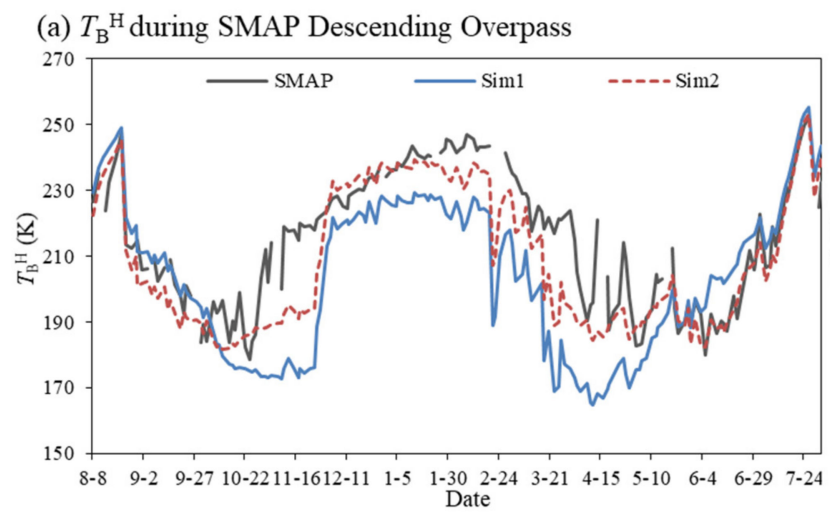

(b) $T_{\mathrm{B}} \mathrm{V}$ during SMAP Descending Overpass

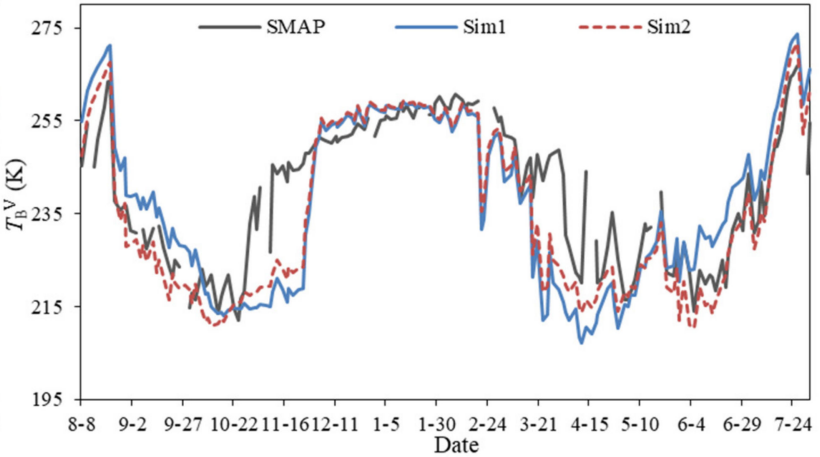

(c) $T_{\mathrm{B}}{ }^{\mathrm{H}}$ during SMAP Ascending Overpass

(d) $T_{\mathrm{B}} \mathrm{v}$ during SMAP Ascending Overpass
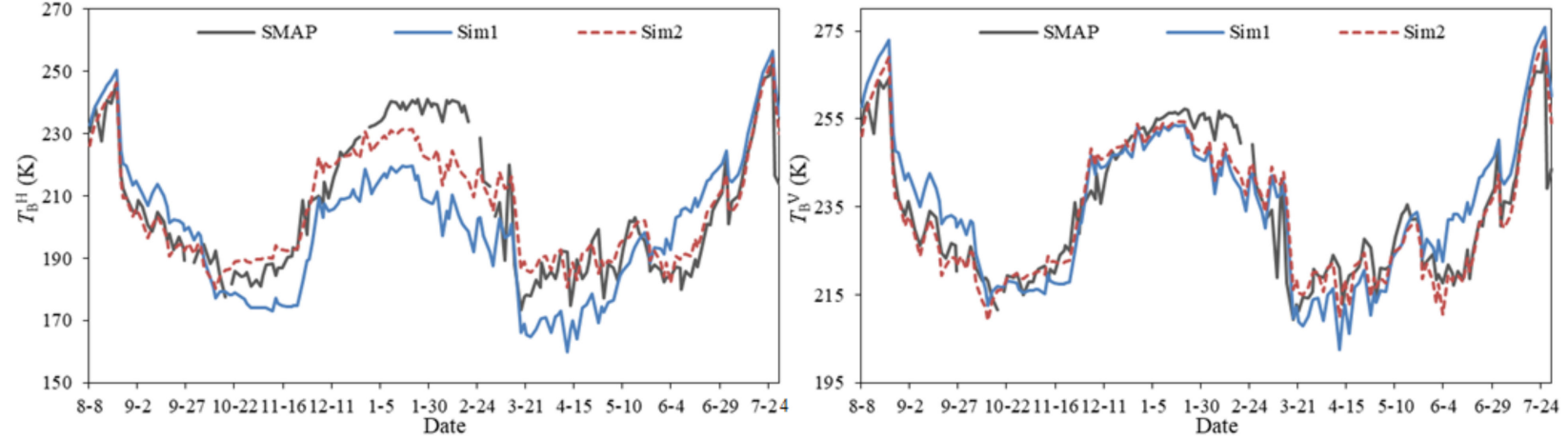

Figure 6. Time series of the $\operatorname{SMAP}(\mathbf{a}, \mathbf{c}) T_{\mathrm{B}}{ }^{\mathrm{H}}$ and $(\mathbf{b}, \mathbf{d}) T_{\mathrm{B}}{ }^{\mathrm{V}}$ measurements and simulations performed for the SMAP footprint during the SMAP descending $(\mathbf{a}, \mathbf{b})$ and ascending $(\mathbf{c}, \mathbf{d})$ overpasses between August 2016 and July 2017. Sim1: two-stream emission model configured with SMAP parameterization; Sim2: Zheng's parameterization.

Table 1. Error statistics estimated between the SMAP measured and simulated $T_{\mathrm{B}}{ }^{p}$ performed for the SMAP footprint between August 2016 and July 2017 for the SMAP ascending and descending overpasses. Sim1: SMAP parameterization; Sim2: Zheng's parameterization.

\begin{tabular}{|c|c|c|c|c|c|c|c|c|}
\hline \multirow[b]{2}{*}{ Simulations } & \multicolumn{4}{|c|}{$\mathrm{T}_{\mathrm{B}}{ }^{\mathrm{H}}$} & \multicolumn{4}{|c|}{$T_{B} V$} \\
\hline & ubRMSE (K) & $\begin{array}{l}\text { Bias } \\
\text { (K) }\end{array}$ & RMSE (K) & $\mathbf{R}$ & ubRMSE (K) & Bias (K) & RMSE (K) & $\mathbf{R}$ \\
\hline \multicolumn{9}{|c|}{ Descending } \\
\hline $\operatorname{Sim} 1$ & 16.88 & -11.86 & 20.63 & 0.70 & 11.26 & -2.56 & 11.54 & 0.79 \\
\hline $\operatorname{Sim} 2$ & 9.23 & -6.29 & 11.17 & 0.90 & 8.05 & -4.25 & 9.10 & 0.90 \\
\hline \multicolumn{9}{|c|}{ Ascending } \\
\hline Sim1 & 14.50 & -6.60 & 15.93 & 0.78 & 7.41 & 0.43 & 7.42 & 0.89 \\
\hline $\operatorname{Sim} 2$ & 8.35 & -0.27 & 8.35 & 0.93 & 5.18 & -0.91 & 5.26 & 0.94 \\
\hline
\end{tabular}

Figure 7 further shows the time series of ELBARA-III $T_{\mathrm{B}}{ }^{p}$ measurements and simulations for the off-nadir angle $\psi=40^{\circ}$ produced by both Sim1 and Sim 2 performed for the ELBARA-III footprint during the SMAP overpasses. The corresponding statistical errors estimated between the ELBARA-III measured and simulated $T_{\mathrm{B}}{ }^{p}$ are given in Table 2. Similar to the SMAP case, the Sim2 reduces the $T_{B}{ }^{\mathrm{H}}$ underestimation between November and February and the $T_{\mathrm{B}} \mathrm{V}$ overestimation between June and October noted for the Sim1. In addition, the ELBARA-III measured $T_{\mathrm{B}} \mathrm{V}$ are better captured in comparison to the $T_{\mathrm{B}}{ }^{\mathrm{H}}$ simulation. However, it should be noted that both $T_{\mathrm{B}}{ }^{\mathrm{H}}$ and $T_{\mathrm{B}} \mathrm{V}$ are still underestimated 
between January and February, which is most probably due to the fact that the $\theta_{\text {liq }}$ measurement at $5 \mathrm{~cm}$ soil depth do not necessarily represent well the ELBARA-III sensing depth as reported by Zheng et al. [47,48]. Such underestimations are not found in the simulations performed with Sim2 for the large-scale SMAP $T_{\mathrm{B}}{ }^{p}$ measurements, which is consistent with the better agreements noted between SMAP measurements and the in situ $\theta_{\text {liq }}$ (see Section 4.2).

(a) $T_{\mathrm{B}}{ }^{\mathrm{H}}$ during SMAP Descending Overpass

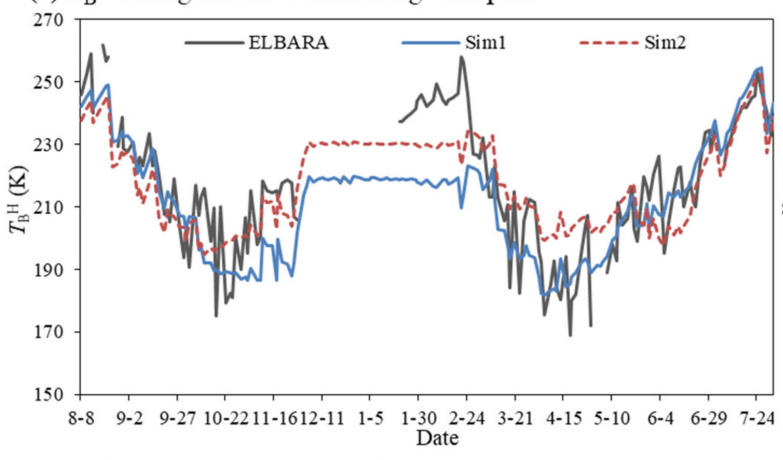

(c) $T_{\mathrm{B}}{ }^{\mathrm{H}}$ during SMAP Ascending Overpass

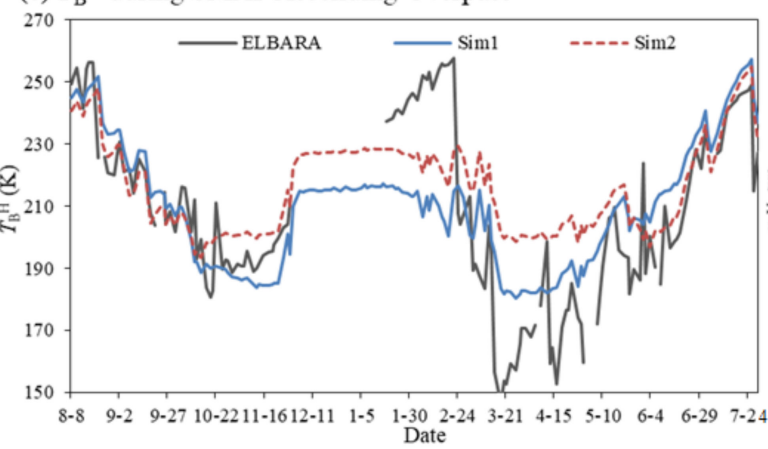

(b) $T_{\mathrm{B}} \mathrm{V}$ during SMAP Descending Overpass

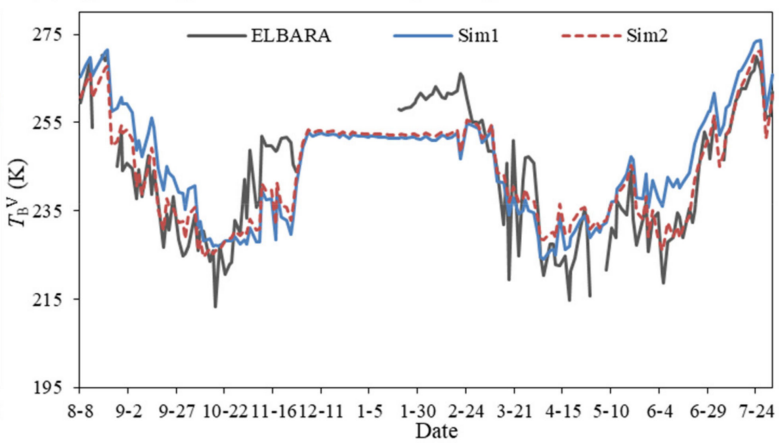

(d) $T_{\mathrm{B}} \mathrm{V}$ during SMAP Ascending Overpass

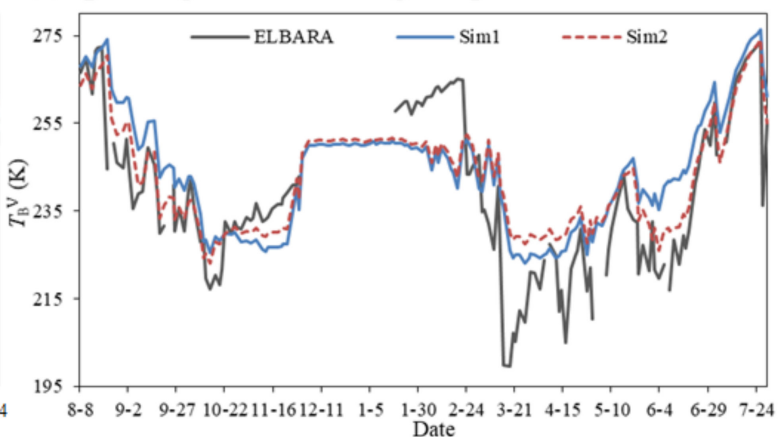

Figure 7. Time series of the ELBARA-III $(\mathbf{a}, \mathbf{c}) T_{\mathrm{B}}{ }^{\mathrm{H}}$ and $(\mathbf{b}, \mathbf{d}) T_{\mathrm{B}} \mathrm{V}$ measurements and simulations performed for the ELBARA-III footprint during the SMAP descending $(\mathbf{a}, \mathbf{b})$ and ascending $(\mathbf{c}, \mathbf{d})$ overpasses between August 2016 and July 2017. Sim1: two-stream emission model configured with SMAP parameterization; Sim2: Zheng's parameterization.

Table 2. Error statistics estimated between the ELBARA-III measured and simulated $T_{\mathrm{B}}{ }^{p}$ performed for the ELBARA-III footprint between August 2016 and July 2017 for the SMAP ascending and descending overpasses. Sim1: SMAP parameterization; Sim2: Zheng's parameterization.

\begin{tabular}{|c|c|c|c|c|c|c|c|c|}
\hline \multirow[b]{2}{*}{ Simulations } & \multicolumn{4}{|c|}{$\mathbf{T}_{\mathbf{B}}{ }^{\mathrm{H}}$} & \multicolumn{4}{|c|}{$T_{B} V^{V}$} \\
\hline & ubRMSE (K) & $\begin{array}{c}\text { Bias } \\
(\mathrm{K})\end{array}$ & RMSE (K) & $\mathbf{R}$ & ubRMSE (K) & Bias (K) & RMSE (K) & $\mathbf{R}$ \\
\hline \multicolumn{9}{|c|}{ Descending } \\
\hline Sim1 & 12.72 & -6.82 & 14.43 & 0.81 & 9.03 & 1.19 & 9.11 & 0.80 \\
\hline $\operatorname{Sim} 2$ & 12.29 & -1.76 & 12.41 & 0.83 & 7.08 & -0.43 & 7.09 & 0.88 \\
\hline \multicolumn{9}{|c|}{ Ascending } \\
\hline Sim1 & 18.34 & 0.97 & 18.36 & 0.76 & 10.56 & 3.76 & 11.21 & 0.80 \\
\hline $\operatorname{Sim} 2$ & 18.70 & 6.74 & 19.88 & 0.78 & 9.67 & 2.51 & 9.99 & 0.85 \\
\hline
\end{tabular}

\subsection{Soil Liquid Water Content Retrieval}

The two-stream emission model configured with the four-phase soil dielectric model (see Section 3.1) is adopted by the SCA-V, SCA-H and DCA algorithms (see Section 3.2) to retrieve the $\theta_{\text {liq, }}$, whereby Zheng's vegetation and surface roughness parameterization is implemented to estimate the parameters $\tau, h$, and $Q$ due to its better performance (see 
Section 4.3). Both ELBARA-III and SMAP measured $T_{\mathrm{B}}{ }^{\mathrm{H}}$ and $T_{\mathrm{B}}{ }^{\mathrm{V}}$ during both ascending and descending overpasses are used to retrieve the $\theta_{\text {liq }}$ for both cold and warm periods, and the in situ $\theta_{\text {liq }}$ representative of both ELBARA-III and SMAP footprints measured at $5 \mathrm{~cm}$ depth are utilized to identify the optimum retrievals.

Figure $8 \mathrm{a}, \mathrm{b}$ show the time series of in situ $\theta_{\text {liq }}$ representative of SMAP footprint (black line) and the retrieved $\theta_{\text {liq }}$ obtained by the SCA-V, SCA-H and DCA algorithms (colored lines) based on the SMAP $T_{\mathrm{B}}{ }^{p}$ measurements during the period between August 2016 and July 2017 for the descending and ascending overpasses, respectively. Corresponding statistical errors estimated between the $\theta_{\text {liq }}$ measurements and retrievals are given in Table 3. For the comparison purpose, the $\theta_{\text {liq }}$ retrieval derived from the SMAP radiometer soil moisture product (see Section 2.3) is also presented in Figure 8 (orange line). It can be found that the SMAP $\theta_{\text {liq }}$ retrieval is only available for the warm season since the adopted soil dielectric mixing model developed by Mironov et al. [25] is only suitable for thawed soil condition. On the contrary, the SCA-V, SCA-H and DCA approaches configured with the four-phase soil dielectric mixing model are able to retrieve $\theta_{\text {liq }}$ for both cold and warm periods in this study. In general, the retrieved $\theta_{\text {liq }}$ obtained by the SCA-V, SCA-H and DCA approaches based on the SMAP $T_{\mathrm{B}}{ }^{p}$ measurements are comparable to each other, which capture well both magnitudes and dynamics of in situ $\theta_{\text {liq }}$ representative of SMAP footprint for both warm and cold seasons during both descending and ascending overpasses. In addition, all the $\theta_{\text {liq }}$ retrievals produced in this study are better than the SMAP $\theta_{\text {liq }}$ product, and the latter tends to underestimate the $\theta_{\text {liq }}$ measurements due to poorer performance of SMAP default vegetation and surface roughness parameterizations (Section 4.3). It can be noted that all the $\theta_{\text {liq }}$ retrievals including SMAP product underestimate the $\theta_{\text {liq }}$ measurements for the transition seasons with soil thawing from March and April and soil freezing between October and November during the descending overpass due to underestimations of both $T_{\mathrm{B}}{ }^{\mathrm{H}}$ and $T_{\mathrm{B}} \mathrm{V}$ simulations (see Figure 6). Such underestimations, however, disappeared in the SMAP ascending overpass for the $\theta_{\text {liq }}$ retrievals produced in this study. The reason can be that the spatial heterogeneity of soil freezing is not fully represented by the measured $\theta_{\text {liq }}$ representative of SMAP footprint as also given in Zheng et al. [16]. The error statistics shown in Table 3 reflect the better performance of $\theta_{\text {liq }}$ retrievals obtained with the SCA-V than with SCA-H or DCA especially during the ascending overpass as indicated by lower RMSE and ubRMSE values. This finding supports the use of the SCA-V approach as the baseline soil moisture retrieval algorithm of the SMAP mission [56] for the Tibetan environments. Notably, the SCA- $V$ gives the best $\theta_{\text {liq }}$ retrievals that match the average $\theta_{\text {liq }}$ measurements of the SMAP footprint, especially when the SMAP $T_{\mathrm{B}} \mathrm{V}$ measured during the ascending overpass are used. For these circumstances, an ubRMSE $=0.035 \mathrm{~m}^{3} \mathrm{~m}^{-3}$ is produced, which outperforms the mission goal of SMAP with an expected ubRMSE of $0.04 \mathrm{~m}^{3} \mathrm{~m}^{-3}$ [4]. This indicates that the SMAP $T_{\mathrm{B}} \mathrm{V}$ measurements during the ascending overpass can be the better choice to retrieve the $\theta_{\text {liq }}$ for both warm and cold periods using the SCA-V approach.
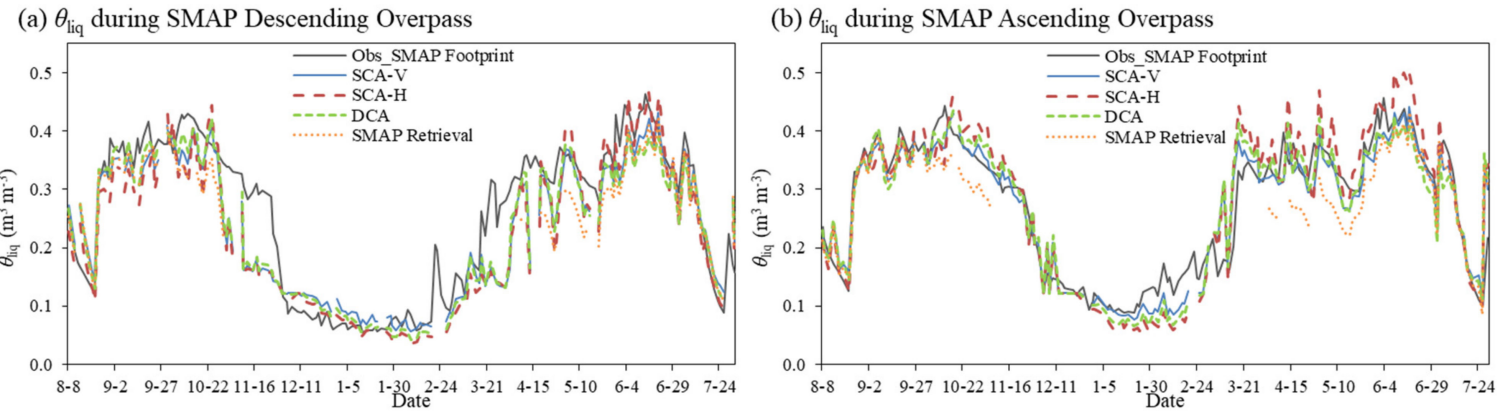

Figure 8. Time series of average $\theta_{\text {liq }}$ measurements of SMAP footprint and retrievals obtained by the SCA-V, SCA-H and DCA algorithms based on the SMAP measured $T_{\mathrm{B}}{ }^{p}$ for the (a) descending and (b) ascending overpasses between August 2016 and July 2017. The $\theta_{\text {liq }}$ retrieval derived from the SMAP SM product is also shown. 
Table 3. Statistical errors estimated between the in situ average $\theta_{\text {liq }}$ and retrievals obtained by the SCA-V, SCA-H and DCA algorithms using either the ELBARA-III or SMAP measured $T_{\mathrm{B}}{ }^{p}$ during the ascending and descending overpasses between August 2016 and July 2017.

\begin{tabular}{|c|c|c|c|c|c|c|c|c|}
\hline \multirow[b]{2}{*}{ Retrievals } & \multicolumn{4}{|c|}{ SMAP Footprint } & \multicolumn{4}{|c|}{ ELBARA Footprint } \\
\hline & $\begin{array}{l}\text { ubRMSE } \\
\left(m^{3} m^{-3}\right)\end{array}$ & $\begin{array}{c}\text { Bias } \\
\left(\mathrm{m}^{3} \mathrm{~m}^{-3}\right)\end{array}$ & $\begin{array}{c}\text { RMSE } \\
\left(\mathrm{m}^{3} \mathrm{~m}^{-3}\right)\end{array}$ & $\mathbf{R}$ & $\begin{array}{l}\text { ubRMSE } \\
\left(\mathrm{m}^{3} \mathrm{~m}^{-3}\right)\end{array}$ & $\begin{array}{c}\text { Bias } \\
\left(\mathrm{m}^{3} \mathrm{~m}^{-3}\right)\end{array}$ & $\begin{array}{c}\text { RMSE } \\
\left(\mathrm{m}^{3} \mathrm{~m}^{-3}\right)\end{array}$ & $\mathbf{R}$ \\
\hline & & & & Descending & & & & \\
\hline SCA-V & 0.053 & -0.025 & 0.059 & 0.91 & 0.045 & -0.003 & 0.045 & 0.90 \\
\hline SCA-H & 0.055 & -0.032 & 0.064 & 0.90 & 0.070 & -0.011 & 0.070 & 0.76 \\
\hline DCA & 0.051 & -0.027 & 0.057 & 0.92 & 0.053 & -0.009 & 0.054 & 0.85 \\
\hline & & & & Ascending & & & & \\
\hline SCA-V & 0.035 & -0.005 & 0.035 & 0.95 & 0.063 & 0.021 & 0.067 & 0.84 \\
\hline SCA-H & 0.048 & 0.007 & 0.049 & 0.94 & 0.103 & 0.052 & 0.115 & 0.73 \\
\hline DCA & 0.040 & -0.004 & 0.041 & 0.94 & 0.085 & 0.037 & 0.092 & 0.78 \\
\hline
\end{tabular}

Figure 9 further shows the time series of measured $\theta_{\text {liq }}$ representative of ELBARAIII footprint (black line) and retrieved $\theta_{\text {liq }}$ obtained by the three SM retrieval algorithms (colored lines) using the ELBARA-III measured $T_{\mathrm{B}}{ }^{p}$ at the observation angle of $40^{\circ}$. Corresponding statistical errors estimated between the measured $\theta_{\text {liq }}$ and associated retrievals are also provided in Table 3 . As in the case for the retrievals using the SMAP $T_{\mathrm{B}}{ }^{p}$ measurements, the SCA-V algorithm also outperforms the two other methods (i.e., DCA and SCA-H) in retrieving the $\theta_{\text {liq }}$ using the ELBARA-III measurements for both warm and cold seasons during both descending and ascending overpasses as indicated by lower values of bias, RMSE and ubRMSE and higher $R$ values. In comparison to the $\theta_{\text {liq }}$ retrievals produced based on the SMAP measured $T_{\mathrm{B}}{ }^{p}$, the retrievals produced using the ELBARA-III measurements show poorer performance during the transition seasons with soil thawing (e.g., March and April) and freezing (e.g., October and November). Particularly, the $\theta_{\text {liq }}$ retrievals tend to largely overestimate the in situ $\theta_{\text {liq }}$ representative of ELBARA-III footprint between March and April, which can be related to the thawing of the snowpack that would affect the ELBARA-III measurements.

(a) $\theta_{\text {liq }}$ during SMAP Descending Overpass

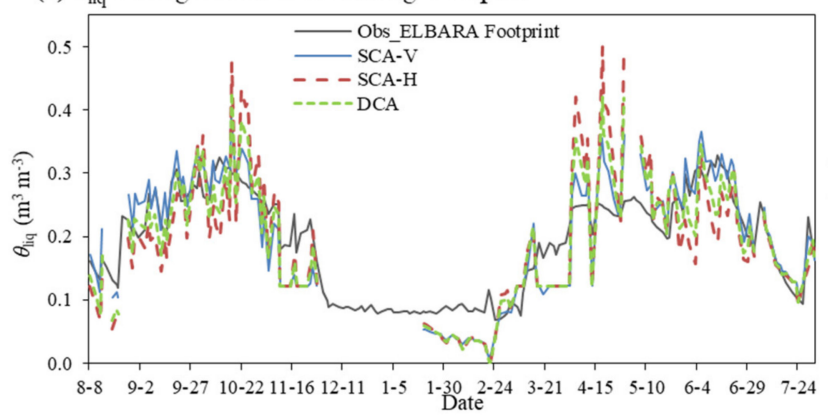

(b) $\theta_{\text {liq }}$ during SMAP Ascending Overpass

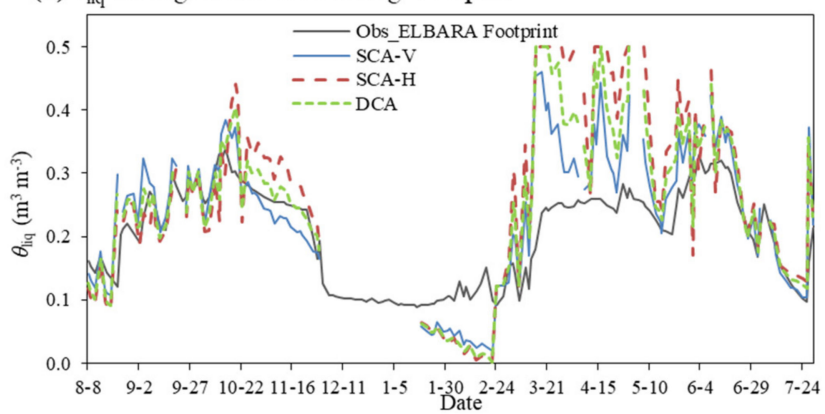

Figure 9. Time series of average $\theta_{\text {liq }}$ measurements of ELBARA-III footprint and retrievals obtained by the SCA-V, SCA-H and DCA algorithms based on the ELBARA-III measured $T_{\mathrm{B}}{ }^{p}$ measurements for the (a) descending and (b) ascending overpasses between August 2016 and July 2017.

\section{Conclusions}

This study investigates the performance of the two-stream microwave emission model in simulating L-band $T_{\mathrm{B}}{ }^{p}$ and retrieving $\theta_{\text {liq }}$ in combination with the four-phase dielectric model for both thawed and frozen soils on the Tibetan Plateau. Both single (SCA) and double (DCA) channel algorithms are adopted using both ground-based ELBARA-III and spaceborne SMAP measurements conducted in a Tibetan grassland site. Intercomparison between the time variations of ELBARA-III and SMAP $T_{\mathrm{B}}{ }^{p}$ measurements demonstrates that high correlations $(R \geq 0.87)$ are found between both measurements, though the foot- 
prints are obviously distinct for the spaceborne SMAP and ground-based ELBARA-III measurements. The SMAP measured $T_{\mathrm{B}}{ }^{p}$ are generally lower than the ELBARA-III measurements between June and October, which are associated with the distinct variations of in situ average $\theta_{\text {liq }}$ found across the ELBARA-III and SMAP footprints. In addition, the analysis of relations between the $T_{\mathrm{B}}{ }^{p}$ measurements and in situ average $\theta_{\text {liq }}$ reveals that (i) SMAP $T_{\mathrm{B}}^{p}$ measurements are better responding to the in situ $\theta_{\text {liq }}$ compared to the ELBARA-III measured $T_{\mathrm{B}}{ }^{p}$, and (ii) the in situ $\theta_{\text {liq }}$ explains better the $T_{\mathrm{B}} \mathrm{V}$ measurements during the warm period from May to October, while $T_{B}{ }^{H}$ measurements are more consistently varying with the in situ $\theta_{\text {liq }}$ in the cold period between November and April.

It is found that the two-stream microwave emission model configured with the default vegetation and surface roughness parameterization of SMAP mission underestimates both ELBARA-III and SMAP measured $T_{B}{ }^{H}$ in the cold season and overestimates the $T_{B} \mathrm{~V}$ measurements in the warm season. The above deficiencies are largely reduced by adopting the new parameterization proposed by Zheng et al. [16], which employs higher values for the roughness parameters $(Q$ and $h)$ and lower values for the vegetation parameter $\tau$. It can also be found that the SMAP measured $T_{\mathrm{B}}{ }^{p}$ are better reproduced with the new parameterization in comparison to the simulations performed for the ELBARA-III footprint, and the simulation of $T_{\mathrm{B}} \mathrm{V}$ outperforms that of $T_{\mathrm{B}}{ }^{\mathrm{H}}$.

In addition, it is found that all the $\theta_{\text {liq }}$ retrievals produced using the SMAP measured $T_{\mathrm{B}}{ }^{p}$ in this study capture well the in situ $\theta_{\text {liq }}$ representative of SMAP footprint and are consistently better than the SMAP product. The $\theta_{\text {liq }}$ retrievals produced using the ELBARAIII measurements show poorer performance in comparison to those generated based on the SMAP measurements. The SCA-V algorithm outperforms both DCA and SCA-H methods in retrieving the $\theta_{\text {liq, }}$, which supports implementing the SCA-V method as the baseline soil moisture retrieval algorithm for the SMAP mission. Notably, the $\theta_{\text {liq }}$ retrievals using the SCA-V based on the SMAP $T_{\mathrm{B}} \mathrm{V}$ measured during the ascending overpass gives the best results (ubRMSE $=0.035 \mathrm{~m}^{3} \mathrm{~m}^{-3}$ ), which is also better than the specified goal of $\mathrm{ubRMSE}=0.04 \mathrm{~m}^{3} \mathrm{~m}^{-3}$ for the SMAP mission.

This study shows the potential of using a two-stream model configured with the four-phase soil dielectric model for simulating L-band $T_{\mathrm{B}}{ }^{p}$ and retrieving $\theta_{\text {liq }}$ for both thawed and frozen soil conditions. It's also noted that the SCA-V algorithm configured with the SMAP measured $T_{\mathrm{B}} \mathrm{V}$ during the ascending overpass is able to produce reliable $\theta_{\text {liq }}$ retrievals in a Tibetan meadow ecosystem. These findings are crucial for improving emission simulation and $\theta_{\text {liq }}$ retrievals at the L-band in cold regions such as the Tibetan Plateau. However, additional work is still needed to investigate and test the performance of the proposed method for its application in other areas. Recently, Li et al. [7] have implemented the two-stream model to simulate the $T_{\mathrm{B}}{ }^{p}$ and retrieve soil moisture using SMOS measurements at a global scale, which provides an excellent reference to extend the application of the method proposed in this study. For example, the soil dielectric model, and the adopted vegetation and surface roughness parameterization for grassland used by Li et al. [7] can be directly replaced by the four-phase soil dielectric model and new parameterization proposed in this study to improve its performance in a cold region such as the Tibetan Plateau. The needed SMST data can be taken from the reanalysis data such as the ECMWF model simulations carried out by Li et al. [7].

Supplementary Materials: The following are available online at https:/ / www.mdpi.com/article/ $10.3390 / \mathrm{rs} 14030494 / \mathrm{s} 1$, Supplementary Table S1: Measurements of brightness temperature and liquid soil water content; Supplementary Table S2: Sample computation for implementing the two-stream model with SMAP or Zheng's parameterization.

Funding: This research was supported by the National Natural Science Foundation of China (grant number 41901317).

Institutional Review Board Statement: Not applicable.

Informed Consent Statement: Not applicable. 
Data Availability Statement: Not applicable.

Conflicts of Interest: The authors declare no conflict of interest.

\section{References}

1. Entekhabi, D.; Njoku, E.G.; O’Neill, P.E.; Kellogg, K.H.; Crow, W.T.; Edelstein, W.N.; Entin, J.K.; Goodman, S.D.; Jackson, T.J.; Johnson, J.; et al. The Soil Moisture Active Passive (SMAP) Mission. Proc. IEEE 2010, 98, 704-716. [CrossRef]

2. Kerr, Y.H.; Waldteufel, P.; Richaume, P.; Wigneron, J.P.; Ferrazzoli, P.; Mahmoodi, A.; Al Bitar, A.; Cabot, F.; Gruhier, C.; Juglea, S.E.; et al. The SMOS soil moisture retrieval algorithm. IEEE Trans. Geosci. Remote Sens. 2012, 50, 1384-1403. [CrossRef]

3. Mo, T.; Choudhury, B.J.; Schmugge, T.J.; Wang, J.R.; Jackson, T.J. A model for microwave emission from vegetation-covered fields. J. Geophys. Res. Earth Surf. 1982, 87, 11229-11237. [CrossRef]

4. Chan, S.; Bindlish, R.; O’Neill, P.; Jackson, T.; Njoku, E.; Dunbar, S.; Chaubell, J.; Piepmeier, J.; Yueh, S.; Entekhabi, D.; et al. Development and assessment of the SMAP enhanced passive soil moisture product. Remote Sens. Environ. 2017, 204, 931-941. [CrossRef]

5. Wigneron, J.-P.; Jackson, T.; O’Neill, P.; De Lannoy, G.; de Rosnay, P.; Walker, J.; Ferrazzoli, P.; Mironov, V.; Bircher, S.; Grant, J.; et al. Modelling the passive microwave signature from land surfaces: A review of recent results and application to the L-band SMOS \& SMAP soil moisture retrieval algorithms. Remote Sens. Environ. 2017, 192, 238-262.

6. Schwank, M.; Naderpour, R.; Mätzler, C. “Tau-Omega”- and Two-Stream Emission Models Used for Passive L-Band Retrievals: Application to Close-Range Measurements over a Forest. Remote Sens. 2018, 10, 1868. [CrossRef]

7. Li, X.; Al-Yaari, A.; Schwank, M.; Fan, L.; Frappart, F.; Swenson, J.; Wigneron, J.-P. Compared performances of SMOS-IC soil moisture and vegetation optical depth retrievals based on Tau-Omega and Two-Stream microwave emission models. Remote Sens. Environ. 2019, 236, 111502. [CrossRef]

8. Mätzler, C. COST Action 712: Microwave Radiometry. In Remote Sensing of Atmosphere and Ocean from Space: Models, Instruments and Techniques. Advances in Global Change Research; Marzano, F.S., Visconti, G., Eds.; Springer: Dordrecht, The Netherlands, 2002; Volume 13, pp. 231-246. [CrossRef]

9. Feldman, A.F.; Akbar, R.; Entekhabi, D. Characterization of higher-order scattering from vegetation with SMAP measurements. Remote Sens. Environ. 2018, 219, 324-338. [CrossRef]

10. Kurum, M.; O’Neill, P.E.; Lang, R.H.; Joseph, A.T.; Cosh, M.H.; Jackson, T.J. Effective tree scattering and opacity at L-band. Remote Sens. Environ. 2012, 118, 1-9. [CrossRef]

11. Ferrazzoli, P.; Guerriero, L.; Wigneron, J.-P. Simulating L-band emission of forests in view of future satellite applications. IEEE Trans. Geosci. Remote Sens. 2002, 40, 2700-2708. [CrossRef]

12. Santi, E.; Paloscia, S.; Pampaloni, P.; Pettinato, S. Ground-Based Microwave Investigations of Forest Plots in Italy. IEEE Trans. Geosci. Remote Sens. 2009, 47, 3016-3025. [CrossRef]

13. Wigneron, J.-P.; Chnazy, A.; Kerr, Y.H.; Larence, H.; Shi, J.; Escorihuela, M.J.; Mironov, V.; Mialon, A.; Demontoux, F.; de Rosnay, P.; et al. Evaluating an improved parameterization of the soil emission in L-MEB. IEEE Trans. Geosci. Remote Sens. 2011, 49, 1177-1189. [CrossRef]

14. Rahmoune, R.; Ferrazzoli, P.; Kerr, Y.H.; Richaume, P. SMOS Level 2 Retrieval Algorithm Over Forests: Description and Generation of Global Maps. IEEE J. Sel. Top. Appl. Earth Obs. Remote Sens. 2013, 6, 1430-1439. [CrossRef]

15. Vittucci, C.; Ferrazzoli, P.; Kerr, Y.; Richaume, P.; Guerriero, L.; Rahmoune, R.; Laurin, G.V. SMOS retrieval over forests: Exploitation of optical depth and tests of soil moisture estimates. Remote Sens. Environ. 2016, 180, 115-127. [CrossRef]

16. Zheng, D.; Wang, X.; van der Velde, R.; Ferrazzoli, P.; Wen, J.; Wang, Z.; Schwank, M.; Colliander, A.; Bindlish, R.; Su, Z. Impact of surface roughness, vegetation opacity and soil permittivity on L-band microwave emission and soil moisture retrieval in the third pole environment. Remote Sens. Environ. 2018, 209, 633-647. [CrossRef]

17. Kurum, M. Quantifying scattering albedo in microwave emission of vegetated terrain. Remote Sens. Environ. 2013, 129, 66-74. [CrossRef]

18. Mätzler, C. Improved Born approximation for scattering of radiation in a granular medium. J. Appl. Phys. 1998, 83, 6111-6117. [CrossRef]

19. Wiesmann, A.; Mätzler, C. Microwave Emission Model of Layered Snowpacks. Remote Sens. Environ. 1999, 70, 307-331. [CrossRef]

20. Naderpour, R.; Schwank, M. Snow Wetness Retrieved from L-Band Radiometry. Remote Sens. 2018, 10, 359. [CrossRef]

21. Schwank, M.; Naderpour, R. Snow Density and Ground Permittivity Retrieved from L-Band Radiometry: Melting Effects. Remote Sens. 2018, 10, 354. [CrossRef]

22. Zhang, T.; Barry, R.G.; Knowles, K.W.; Ling, F.; Armstrong, R. Distribution of seasonally and perennially frozen ground in the Northern Hemisphere. In Proceedings of the 8th International Conference on Permafrost; AA Balkema Publishers: Zürich, Switzerland, 2003; Volume 2, pp. 1289-1294.

23. Kim, Y.; Kimball, J.S.; McDonald, K.C.; Glassy, J. Developing a Global Data Record of Daily Landscape Freeze/Thaw Status Using Satellite Passive Microwave Remote Sensing. IEEE Trans. Geosci. Remote Sens. 2010, 49, 949-960. [CrossRef]

24. Rautiainen, K.; Parkkinen, T.; Lemmetyinen, J.; Schwank, M.; Wiesmann, A.; Ikonen, J.; Derksen, C.; Davydov, S.; Davydova, A.; Boike, J.; et al. SMOS prototype algorithm for detecting autumn soil freezing. Remote Sens. Environ. 2016, 180, 346-360. [CrossRef] 
25. Mironov, V.; Kerr, Y.; Wigneron, J.-P.; Kosolapova, L.; Demontoux, F. Temperature- and Texture-Dependent Dielectric Model for Moist Soils at 1.4 GHz. IEEE Geosci. Remote Sens. Lett. 2012, 10, 419-442. [CrossRef]

26. Dobson, M.C.; Ulaby, F.T.; Hallikainen, M.T.; El-Rayes, M.A. Microwave dielectric behavior of wet soil—Part II: Dielectric mixing models. IEEE Trans. Geosci. Remote Sens 1985, 23, 35-46. [CrossRef]

27. Zhang, L.; Zhao, T.; Jiang, L.; Zhao, S. Estimate of Phase Transition Water Content in Freeze-Thaw Process Using Microwave Radiometer. IEEE Trans. Geosci. Remote Sens. 2010, 48, 4248-4255. [CrossRef]

28. Mironov, V.L.; Kosolapova, L.G.; Lukin, Y.I.; Karavaysky, A.Y.; Molostov, I.P. Temperature- and texture-dependent dielectric model for frozen and thawed mineral soils at a frequency of 1.4GHz. Remote Sens. Environ. 2017, 200, 240-249. [CrossRef]

29. Birchak, J.; Gardner, C.; Hipp, J.; Victor, J. High dielectric constant microwave probes for sensing soil moisture. Proc. IEEE 1974, 62, 93-98. [CrossRef]

30. Schwank, M.; Stahli, M.; Wydler, H.; Leuenberger, J.; Matzler, C.; Fluhler, H. Microwave L-band emission of freezing soil. IEEE Trans. Geosci. Remote Sens. 2004, 42, 1252-1261. [CrossRef]

31. Zheng, D.; Li, X.; Zhao, T.; Wen, J.; van der Velde, R.; Schwank, M.; Wang, X.; Wang, Z.; Su, Z. Impact of Soil Permittivity and Temperature Profile on L-Band Microwave Emission of Frozen Soil. IEEE Trans. Geosci. Remote Sens. 2020, 59, 4080-4093. [CrossRef]

32. Wang, R.; Choudhury, B.J. Remote sensing of soil moisture content, over bare field at $1.4 \mathrm{GHz}$ frequency. J. Geophys. Res. Oceans 1981, 86, 5277-5282. [CrossRef]

33. Ulaby, F.T.; Long, D.G. Microwave Radar and Radiometric Remote Sensing; The University of Michigan Press: Ann Arbor, MI, USA, 2014

34. O'Neill, P.; Njoku, E.; Jackson, T.; Chan, S.; Bindlish, R. SMAP Algorithm Theoretical Basis Document: Level 2 E 3 Soil Moisture (Passive) Data Products; Jet Propulsion Laboratory, California Institute of Technology: Pasadena, CA, USA, 2015 ; JPL D-66480.

35. Lawrence, H.; Wigneron, J.-P.; Demontoux, F.; Mialon, A.; Kerr, Y.H. Evaluating the Semiempirical H-Q Model Used to Calculate the L-Band Emissivity of a Rough Bare Soil. IEEE Trans. Geosci. Remote Sens. 2013, 51, 4075-4084. [CrossRef]

36. Moran, R.F.; Wigneron, J.-P.; Lopez-Baeza, E.; Al-Yaari, A.; Coll-Pajaron, A.; Mialon, A.; Miernecki, M.; Parrens, M.; Salgado-Hernanz, P.; Schwank, M.; et al. Roughness and vegetation parameterizations at L-band for soil moisture retrievals over a vineyard field. Remote Sens. Environ. 2015, 170, 269-279. [CrossRef]

37. Goodberlet, M.A.; Mead, J.B. A Model of Surface Roughness for Use in Passive Remote Sensing of Bare Soil Moisture. IEEE Trans. Geosci. Remote Sens. 2013, 52, 5498-5505. [CrossRef]

38. Montpetit, B.; Royer, A.; Wigneron, J.-P.; Chanzy, A.; Mialon, A. Evaluation of multi-frequency bare soil microwave reflectivity models. Remote Sens. Environ. 2015, 162, 186-195. [CrossRef]

39. Zheng, D.; Van Der Velde, R.; Wen, J.; Wang, X.; Ferrazzoli, P.; Schwank, M.; Colliander, A.; Bindlish, R.; Su, Z. Assessment of the SMAP Soil Emission Model and Soil Moisture Retrieval Algorithms for a Tibetan Desert Ecosystem. IEEE Trans. Geosci. Remote Sens. 2018, 56, 3786-3799. [CrossRef]

40. Chaubell, M.J.; Yueh, S.H.; Dunbar, R.S.; Colliander, A.; Chen, F.; Chan, S.K.; Entekhabi, D.; Bindlish, R.; O'Neill, P.E.; Asanuma, J.; et al. Improved SMAP Dual-Channel Algorithm for the Retrieval of Soil Moisture. IEEE Trans. Geosci. Remote Sens. 2020, 58, 3894-3905. [CrossRef]

41. Colliander, A.; Jackson, T.J.; Bindlish, R.; Chan, S.; Das, N.; Kim, S.B.; Cosh, M.H.; Dunbar, R.S.; Dang, L.; Pashaian, L.; et al Validation of SMAP surface soil moisture products with core validation sites. Remote Sens. Environ. 2017, 191, 215-231. [CrossRef]

42. Benninga, H.-J.F.; Carranza, C.D.U.; Pezij, M.; van Santen, P.; van der Ploeg, M.J.; Augustijn, D.C.M.; van der Velde, R. The Raam regional soil moisture monitoring network in the Netherlands. Earth Syst. Sci. Data 2018, 10, 61-79. [CrossRef]

43. Dente, L.; Vekerdy, Z.; Wen, J.; Su, Z. Maqu network for validation of satellite-derived soil moisture products. Int. J. Appl. Earth Obs. Geoinf. 2012, 17, 55-65. [CrossRef]

44. Zheng, D.; van der Velde, R.; Su, Z.; Wang, X.; Wen, J.; Booij, M.J.; Hoekstra, A.Y.; Chen, Y. Augmentations to the Noah Model Physics for Application to the Yellow River Source Area. Part I: Soil Water Flow. J. Hydrometeorol. 2015, 16, 2659-2676. [CrossRef]

45. Zhang, P.; Zheng, D.; van der Velde, R.; Wen, J.; Zeng, Y.; Wang, X.; Wang, Z.; Chen, J.; Su, Z. Status of the Tibetan Plateau observatory (Tibet-Obs) and a 10-year (2009-2019) surface soil moisture dataset. Earth Syst. Sci. Data 2021, 13, 3075-3102. [CrossRef]

46. Schwank, M.; Wiesmann, A.; Werner, C.; Mätzler, C.; Weber, D.; Murk, A.; Völksch, I.; Wegmüller, U. ELBARA II, an L-Band Radiometer System for Soil Moisture Research. Sensors 2010, 10, 584-612. [CrossRef] [PubMed]

47. Zheng, D.; Wang, X.; van der Velde, R.; Zeng, Y.; Wen, J.; Wang, Z.; Schwank, M.; Ferrazzoli, P.; Su, Z. L-Band Microwave Emission of Soil Freezesc-Thaw Process in the Third Pole Environment. IEEE Trans. Geosci. Remote Sens. 2017, 55, 5324-5338. [CrossRef]

48. Zheng, D.; Li, X.; Wang, X.; Wang, Z.; Wen, J.; van der Velde, R.; Schwank, M.; Su, Z. Sampling depth of L-band radiometer measurements of soil moisture and freeze-thaw dynamics on the Tibetan Plateau. Remote Sens. Environ. 2019, $226,16-25$. [CrossRef]

49. Pellarin, T.; Wigneron, J.-P.; Calvet, J.-C.; Berger, M.; Douville, H.; Ferrazzoli, P.; Kerr, Y.; Lopez-Baeza, E.; Pulliainen, J.; Simmonds, L.; et al. Two-year global simulation of L-band brightness temperatures over land. IEEE Trans. Geosci. Remote Sens. 2003, 41, 2135-2139. [CrossRef]

50. Wigneron, J.-P.; Laguerre, L.; Kerr, Y.H. A simple parameterization of the L-band microwave emission from rough agricultural soils. IEEE Trans. Geosci. Remote Sens. 2001, 39, 1697-1707. [CrossRef] 
51. Zheng, D.; Wang, X.; van der Velde, R.; Schwank, M.; Ferrazzoli, P.; Wen, J.; Wang, Z.; Colliander, A.; Bindlish, R.; Su, Z. Assessment of Soil Moisture SMAP Retrievals and ELBARA-III Measurements in a Tibetan Meadow Ecosystem. IEEE Geosci. Remote Sens. Lett. 2019, 16, 1407-1411. [CrossRef]

52. Zheng, D.; van der Velde, R.; Su, Z.; Wen, J.; Wang, X.; Yang, K. Evaluation of Noah Frozen Soil Parameterization for Application to a Tibetan Meadow Ecosystem. J. Hydrometeorol. 2017, 18, 1749-1763. [CrossRef]

53. Choudhury, B.J.; Schmugge, T.J.; Mo, T. A parameterization of effective soil temperature for microwave emission. J. Geophys. Res. Earth Surf. 1982, 87, 1301-1304. [CrossRef]

54. Huete, A.; Didan, K.; Miura, T.; Rodriguez, E.P.; Gao, X.; Ferreira, L.G. Overview of the radiometric and biophysical performance of the MODIS vegetation indices. Remote Sens. Environ. 2001, 83, 195-213. [CrossRef]

55. Myneni, R.; Knyazikhin, Y.; Park, T. MCD15A3H MODIS/Terra+Aqua Leaf Area Index/FPAR 4-Day L4 Global 500m SIN Grid V006 NASA EOSDIS Land Processes DAAC. 2015. Available online: https:/ / modis.gsfc.nasa.gov/data/dataprod/mod15.php (accessed on 12 December 2021).

56. Chan, S.K.; Bindlish, R.; O’Neill, P.E.; Njoku, E.; Jackson, T.; Colliander, A.; Chen, F.; Burgin, M.; Dunbar, S.; Piepmeier, J.; et al. Assessment of the SMAP Passive Soil Moisture Product. IEEE Trans. Geosci. Remote Sens. 2016, 54, 4994-5007. [CrossRef] 